\title{
O Ensino Testemunhal entre os Restos da Ditadura: uma Metodologia Ético-política
}

\author{
Helena Pillar Kessler \\ Universidade Federal do Rio Grande do Sul, RS, Brasil. \\ Marina da Rocha Rodrigues \\ Universidade Federal do Rio Grande do Sul, RS, Brasil.
}

\author{
Daniel Boianovsky Kveller \\ Universidade Federal do Rio Grande do Sul, RS, Brasil. \\ Karine Shamash Szuchman \\ Universidade Federal do Rio Grande do Sul, RS, Brasil.
}

Resumo: O presente artigo tem por objetivo principal apresentar o exercício testemunhal como um potente método de ensino ético-político, por meio do relato de uma experiência de docência em um curso de graduação de Psicologia do Rio Grande do Sul. Propusemos uma disciplina chamada "O que resta da ditadura: estudos clínico-políticos sobre violência", que teve como finalidade estudar os efeitos traumáticos da violência, a função testemunhal como possibilidade de transmissão e elaboração e as implicações desses temas para o trabalho de psicólogos(as) no Brasil. Iniciamos nosso relato descrevendo como tornamos as noções de trauma e testemunho ferramentas de ensino. Situamos, assim, a origem e a importância desses conceitos para os campos da psicanálise, da literatura e da história, propondo também uma maneira de utilizá-los como recursos pedagógicos. A seguir, narramos alguns episódios que levaram à emergência de uma "crise" em sala de aula. Discutimos essa crise como uma soma de fatores, destacando-a como um processo próprio da experiência de ensino e justificando, desta feita, que todo ensino testemunhal deve passar por uma crise. Por fim, resumimos os principais aspectos que caracterizam o ensino testemunhal, tal como o entendemos, e analisamos por que ele é uma ferramenta potente na formação de psicólogos(as) na atual conjuntura social e política.

Palavras-chave: Testemunho, Educação, Ditadura Civil-militar, Psicanálise.

\section{Testimonial Teaching among the Remains of the Dictatorship: An Ethical-political Methodology}

\begin{abstract}
The main purpose of this article is to present testimonial exercise as a powerful method of ethico-political teaching, by reporting of a teaching experience in a psychology undergraduate course in Rio Grande do Sul. We proposed a course called "What remains of dictatorship: clinical-political studies of violence" to study the traumatic effects of violence, the role of testimony as a possibility of transmission and working-through, and the implications of these themes for the work of psychologists in Brazil. We begin our account by describing made the notions of trauma and testimony can be incorporated as teaching tools. We thus locate the origin and importance of these concepts for the fields of psychoanalysis, literature and history; also proposing a way of using them as pedagogical tools. After that, we narrate some episodes that led to the emergence of a "crisis" in the classroom. We discuss this crisis as a sum of factors, highlighting it as an inherent process of the teaching experience and justifying, therefore, that all testimonial education must go through a crisis. Finally, we summarize the main aspects that characterize testimonial teaching, as we understand it, and analyze why it is a powerful tool in the education of psychologists in the current social and political conjuncture.
\end{abstract}

Keywords: Testimony, Education, Civil-military Dictatorship, Psychoanalysis. 


\title{
La Enseñanza Testimonial entre los Restos de la Dictadura: una Metodología Ético-política
}

\begin{abstract}
Resumen: El presente artículo tiene por objetivo principal presentar el ejercicio testimonial como un potente método de enseñanza ético-político, a través del relato de una experiencia de docencia en un curso de pregrado de psicología de Rio Grande do Sul. Propusimos una disciplina llamada "Lo que queda de la dictadura: estudios clínico-políticos sobre la violencia", que tuvo como finalidad estudiar los efectos traumáticos de la violencia, la función testimonial como posibilidad de transmisión y elaboración, y las implicaciones de esos temas para el trabajo de psicólogos(as) en Brasil. Iniciamos nuestro relato describiendo cómo hicimos las nociones de trauma y testimonio herramientas de enseñanza. Situamos así el origen y la importancia de estos conceptos para los campos del psicoanálisis, de la literatura y de la historia; proponiendo también una manera de utilizarlos como recursos pedagógicos. A continuación, relatamos algunos episodios que llevaron a la emergencia de una "crisis" en el aula. Discutimos esa crisis como una suma de factores, destacándola como un proceso propio de la experiencia de enseñanza y justificando, así, que toda educación testimonial debe pasar por una crisis. Finalmente, resumimos los principales aspectos que caracterizan la enseñanza testimonial, tal como la entendemos, y analizamos por qué es una herramienta potente en la formación de psicólogos(as) en la actual coyuntura social y política.
\end{abstract}

Palabras claves: Testimonio, Educación, Dictadura Civil-militar, Psicoanálisis.

Engana-se e priva-se do melhor quem se limitar a fazer o inventário dos achados, e não for capaz de assinalar, no terreno do presente, o lugar exato em que guarda as coisas do passado. Walter Benjamin (2014)

\section{Introdução}

Ao longo do século XX, a Psicologia não apenas consolidou-se como um campo específico de conhecimento, mas, também, simultaneamente, ajudou a construir o mundo em que vivemos e os sujeitos que nos tornamos. De acordo com Rose (2008), convém situarmos tal processo como resposta a uma crescente demanda por regulação institucional: nas fábricas, escolas e prisões, por exemplo, a Psicologia foi cada vez mais convocada a constituir saberes científicos que permitissem administrar, regular e classificar pessoas com maior eficiência, produtividade e menor custo. É atendendo a esses pedidos, disfarçada sob as vestes da neutralidade e da objetividade, que a Psicologia ganha espaço e se constitui majoritaria- mente como uma técnica disciplinar, dedicada vigilante das fronteiras biopolíticas a dividir o normal do patológico, o adequado do impróprio e o promissor do intratável (Nardi, \& Silva, 2004).

Não é de se espantar, portanto, que a Psicologia tenha sido também uma confiável aliada de alguns dos regimes totalitários que marcaram os últimos cem anos. No caso brasileiro, como afirma Coimbra (2009), é notória a cumplicidade de psicólogas e psicólogos com práticas de violência de Estado durante a ditadura civil-militar (1964-1985), sendo um dos exemplos paradigmáticos da colaboração da categoria a elaboração de um "perfil psicológico do terrorista brasileiro". A própria regulamentação da profissão ${ }^{1} \mathrm{e}$ a abertura dos primeiros cursos de graduação se deu nesse período, fatos que de forma alguma podem ser tratados como mera coincidência. É igualmente oportuno notar que foi justamente a Psicologia dita "oficial" - aquela que se arroga a prerrogativa de enunciar a última verdade, uma vez que se diz "mais científica", "mais neutra" e "mais objetiva" - a corrente que mais intensamente se submeteu ao aparelho repressivo do

${ }^{1}$ O Conselho Federal de Psicologia e os Conselhos Regionais foram criados pela Lei no 5.766, de 20 de dezembro de 1971, regulamentada

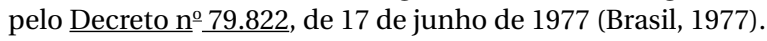


Estado, oferecendo-se como ferramenta de normalização social (Scarparo, Torres, \& Ecker, 2014, p. 73).

Nesse sentido, levando em consideração os acontecimentos políticos que têm novamente colocado em xeque o estatuto democrático de nossa república nos últimos anos, bem como a importância das universidades na formação de psicólogas e psicólogos, perguntamo-nos: como pensar uma formação acadêmica crítica do fazer $p s i$ ? Como pensar uma formação que se contraponha à primazia da técnica e da pretensa "neutralidade" para valorizar também a análise de implicação com a conjuntura social de nosso país? Como formar psicólogas e psicólogos capazes de trabalhar a memória das décadas vividas sob Estado de exceção a partir de um outro referencial ético-político? Partindo de tais questionamentos, o presente artigo indica uma possível direção de trabalho ao apontar o testemunho como uma potente metodologia de ensino. Para tanto, realizaremos um relato de nossa experiência como docentes em um curso de graduação em Psicologia do Rio Grande do Sul.

A docência em questão aconteceu durante o primeiro semestre do ano de 2016. Propusemos uma disciplina chamada "O que resta da ditadura: estudos clínico-políticos sobre violência”, que teria como objetivo estudar as lógicas de reprodução da violência estatal, seus efeitos traumáticos e suas implicações para a formação de psicólogas e psicólogos no Brasil. Como será detalhado nas próximas seções, dividimos o cronograma em módulos temáticos, destacamos alguns conceitos centrais a serem trabalhados e definimos nossa metodologia como um "ensino testemunhal", tomando de empréstimo a expressão cunhada por Felman (2000, p. 68). Propusemos olhar para os "restos" de um passado pouco elaborado para pensar os desafios do tempo presente e, assim, refletir sobre as implicações profissionais e éticas do nosso trabalho como psicólogas e psicólogos frente às diversas violências de Estado. Não poderíamos ter imaginado, entretanto, que a nossa proposta, os acontecimentos políticos que tomavam conta das ruas do país na época e as próprias vivências das alunas e dos alunos fariam emergir uma inusitada "crise" em sala de aula; e que essa crise, por sua vez, se revelaria a própria condição de um ensino testemunhal tal como o pensamos.

Iniciaremos nosso relato descrevendo como tornamos as noções de trauma e testemunho ferramentas de ensino. Situaremos, assim, a origem e a importância desses conceitos para os campos da psi- canálise, da literatura e da história, propondo também uma maneira de utilizá-los como recursos pedagógicos. A seguir, narraremos alguns episódios que levaram à emergência do que chamamos de uma crise em sala de aula, um momento em que a nossa proposta de ensino foi posta em questão pela dinâmica que nós mesmos havíamos sugerido. Discutiremos como essa crise foi, na verdade, um processo necessário nessa experiência, e arriscaremos afirmar que todo ensino testemunhal deve, por sua própria singularidade, passar por uma crise. Por fim, resumiremos os principais aspectos que caracterizam o ensino testemunhal, tal como o entendemos, e analisaremos por que ele é uma ferramenta potente na formação de psicólogas e psicólogos na atual conjuntura social brasileira.

\section{O testemunho como metodologia}

A disciplina "O que resta da ditadura: estudos clínico-políticos sobre violência” foi oferecida como eletiva no currículo do curso de graduação em Psicologia e fez parte do estágio de docência de três mestrandas e um mestrando. Destacamos os "restos" como questão central por entender que a transição brasileira para a nossa nova democracia foi, acima de tudo, um acordo entre as elites - "uma reconciliação extorquida" (Gagnebin, 2010, p. 177) - que privilegiou a manutenção do poder e negligenciou diversas obrigações institucionais próprias à justiça de transição, à construção da memória e à reparação dos danos causados pela violência de Estado. Sublinhamos a importância de levar essas discussões para a universidade e para a formação em Psicologia dentro de um permanente exercício ético e crítico diante da posição que ocupamos. Assim, o objetivo principal da disciplina foi estudar o impacto daquilo que permaneceu, os efeitos traumáticos da violência, a função testemunhal como possibilidade de transmissão e elaboração e a implicação desses temas para o trabalho de psicólogas e psicólogos no Brasil.

Para compor esse diálogo, pareceu-nos interessante lançar mão das noções de "trauma" e "testemunho" como guias conceituais no percurso de ensino ao longo do semestre. A noção de trauma ganhou importância inicialmente no campo da psicanálise, relacionada à vivência de um ou mais acontecimentos aterrorizantes, inesperados e incontroláveis que adquirem um caráter de excesso para o sujeito. De acordo com Freud (1920/2010), a intempestividade e a violência da situação traumática impedem que o 
aparelho psíquico organize suas defesas, o que gera uma "invasão" de estímulos desconectados. A tentativa de "ligação" desse excesso ao sistema de representações psíquico se daria mediante ações repetitivas que se apresentam na forma de compulsão, tais como pesadelos, flashbacks, e outros tipos de revivências. Levando o sujeito a reviver a situação traumática, essas seriam formas de tentar apreender aquilo que ficou sem significação, de tramar sentidos possíveis a posteriori (nachträglich) ou, como diria Endo (2005), de "refazer o caminho desconhecido do trauma [...], agora com o ego de prontidão" (p. 146).

Vale lembrar que a raiz indo-europeia do termo indica que a palavra trauma pode significar "friccionar", "triturar", "perfurar", mas também "suplantar", "passar através". Essa proposição acentua o caráter paradoxal da experiência traumática, que pode se referir tanto ao evento "perfurante" e inesperado que se torna inassimilável ou incompreensível para o sujeito que o vivencia, quanto para delinear a forma através da qual esta "incompreensão" segue acompanhando-o ao longo de sua história, reproduzindo-se enigmaticamente (Nestrovski, \& Seligmann-Silva, 2000). Nesse sentido, mais do que as especificidades do evento em si, quando se fala em trauma, a ênfase está colocada nas possibilidades singulares de cada sujeito habitar um limiar oblíquo entre o representável e o irrepresentável, entre a tentativa da lembrança e a necessidade do esquecimento, entre a colocação em palavras e a passagem ao ato.

A noção de trauma também tem sido utilizada para refletir sobre o legado dos grandes episódios violentos que se abateram sobre grupos, povos ou nações inteiras, especialmente aqueles que marcaram o século XX e o início do século XXI, episódios muitas vezes denominados “catástrofes" (Ortega, 2011). Especialmente após Auschwitz, intensificou-se um enigma para a escrita da história: como narrar episódios que desafiam as possibilidades conceituais de representação por seu próprio caráter traumático? Como transmitir a história desses eventos que excedem o que conseguimos dizer deles? Ao mesmo tempo, como não silenciar diante disso que é impossível de dizer, e como impedir o esquecimento do que se passou? A partir dessa necessidade e de sua simultânea impossibilidade, a noção de testemunho, como a narração possível de um evento traumático, ganha especial relevância nos estudos interdisciplinares sobre história, memória e literatura (Seligmann-Silva, 2000).
Desde essa perspectiva, o exercício testemunhal distancia-se da esfera jurídica, em que é utilizado como ferramenta para a obtenção de uma verdade que precisaria ser verificada através de provas, e de um modelo positivista de historiografia, que deve basear-se exclusivamente em documentos e fatos cientificamente verificáveis. $\mathrm{O}$ entendimento que resgatamos sublinha a importância de situar o testemunho em sua estrutura processual (Laub, 1995), lacunar (Agamben, 2008) e ficcional (Gagnebin, 2006), visto que, desde sua inerente incompletude, apresenta-se como uma versão sempre singular, subjetiva e limitada que tenta dar conta do que ficou sem sentido.

No caso dos países latino-americanos que viveram sob ditaduras no contexto da guerra fria, é preciso considerar ainda a recusa deliberada dos regimes ditatoriais em reconhecer as suas próprias práticas de violência, como a tortura e os desaparecimentos forçados. Nesses casos, evidencia-se o teor eminentemente político do exercício testemunhal, que se configura como a própria possibilidade de narração da história das vítimas (Seligmann-Silva, 2005).

Apoiados em Felman (2000), podemos dizer que há uma dimensão de crise inerente ao ato testemunhal. Por uma via, o traumático desafia a linearidade da história, a capacidade representativa da linguagem e confere ao testemunho, portanto, uma potência desestabilizadora. Ao mesmo tempo, como possibilidade de narração de uma "história dos vencidos" (Benjamin, 1996), o testemunho desvela a história como um campo de disputas hermenêuticas onde a verdade oficial sobre o passado deve estar permanentemente em suspensão. Segundo a autora (Felman, 2000), "o testemunho não é autêntico sem essa 'crise', que tem de, precisamente, quebrar e reavaliar categorias e pontos de referência precedentes" (p. 68, grifo nosso). Desde essa perspectiva, pensamos que todo testemunho implica uma surpresa, uma vez que perturba o que até então entendia-se univocamente como o "passado" e faz emergir o impensado e o imprevisto.

Destacamos que estão em jogo as condições de recepção de testemunhos, visto que se tratam de narrativas que não possuem reconhecimento oficial e que, por conseguinte, não raro acabam encapsuladas em zonas de silêncio e compartilhamentos impossíveis (Kupferberg, 2009). Distanciando-nos novamente da esfera jurídica, compreendemos essas condições não mais como uma técnica para extrair provas, e sim como princípios que norteiam uma construção conjunta, 
simbólica e desafiadora entre aquele que fala e aquele que escuta. Afinal, se por um lado o testemunho diz dos limites do que se consegue narrar, por outro aponta para os limites do que suportamos escutar. Sublinhamos, portanto, a necessidade de acolher o relato do outro, tomando a escuta como aposta no exercício da palavra em seu esforço pela transmissão simbólica.

Podemos dizer, em resumo, que o exercício do testemunho compreende sustentar a importância de que histórias de violência sejam recordadas, tanto pelo indivíduo que as viveu como por aqueles a sua volta, e que não sejam simplesmente esquecidas ou negadas. Trata-se de uma recusa do emudecimento, do esforço da enunciação de algo que pode não estar ainda recoberto de sentido. $O$ exercício narrativo inscreve-se, assim, como possibilidade de construção do presente ao romper ciclos de repetição, silenciamento e violência e insistir na tessitura de uma história sobre o que se passou. Uma necessidade que diz menos de uma tarefa técnica e mais de um dever ético-político: escutar aquilo que sobreviveu à violência, implicar-se na história e apropriar-se dela.

Aproximando os conceitos de trauma e testemunho da história brasileira, encontramos no campo de discussões sobre os restos da ditadura civil-militar um terreno fértil para reflexões e desdobramentos, considerando que esse episódio se inscreve como um dos mais recentes de uma série de brutais repetições. Por restos entendemos não apenas as sequelas da violência daquele período, mas sobretudo os corpos estranhos que resistem à passagem do tempo, as lacunas que distanciam a linguagem historiográfica tradicional da linguagem testemunhal estilhaçada pelo trauma, a tensão que habita a construção da memória no contrafluxo da negação e da obliteração (Teles, \& Safatle, 2010).

Ainda hoje, em nossa formação e atuação profissional, quando nos dispomos a escutar sujeitos que são continuamente violentados e violados pelo Estado, testemunhamos a presença desses restos, fragmentos de barbárie que resistem à passagem do tempo. Em se tratando de nosso exercício ético-profissional, apostamos no ensino como espaço para reflexões críticas que possam gerar novos posicionamentos frente a esse contexto. Nasceu assim a proposta de uma disciplina de graduação que visou à construção de contornos possíveis frente aos desafios que o campo nos coloca.

Para estruturar a disciplina, propusemos dividi-la em alguns módulos temáticos. O primeiro teria como objetivo introduzir as questões que orientariam os trabalhos durante o semestre, ou seja, "o que são os restos da ditadura?" e, mais especificamente, "quais as relações desses restos com a formação em Psicologia?”. O segundo módulo seria focado nas aproximações entre clínica, trauma e testemunho e o terceiro, por sua vez, na díade clínica e memória. Ao final de cada um, alunas e alunos deveriam entregar uma narrativa sobre as relações que percebiam entre suas práticas de estágio, pesquisa ou extensão e o que vínhamos estudando sobre os restos da ditadura. A ideia era que as narrativas estabelecessem entre si uma sequência, de modo que pudessem, ao longo do semestre, compor um testemunho próprio do percurso. Tais narrativas poderiam ser feitas de modo livre, utilizando texto escrito, gravação de filmes, canções ou até mesmo a construção de objetos. Tentamos ao máximo não restringir a criatividade das alunas e dos alunos conquanto permanecessem fiéis a uma única condição: a narrativa deveria explicitar, além de reflexões teóricas sobre os conteúdos estudados, suas próprias percepções e afetos.

Para disparar as discussões, contamos com a presença de convidados que compartilharam com o grupo suas vivências ligadas a movimentos sociais; em outros momentos, utilizamos recursos audiovisuais, como curtas-metragens e filmes, ou ainda testemunhos literários. Além disso, as alunas e os alunos foram convidados a falar, participando ativamente dos debates, dando seus próprios testemunhos sobre o processo, trazendo questões e discutindo suas implicações com o tema de aula, compartilhando-os com a turma e docentes.

Assim, ao longo do semestre, por meio da metodologia adotada para os seminários e para as avaliações - o ensino testemunhal -, a turma foi convocada a se colocar na posição de quem fala e de quem escuta. Ao propor um alargamento da noção de testemunho, Felman (2000) sugere que, para além dos tradicionais campos da clínica, ou até mesmo do direito e da história, possa-se pensar a prática do testemunho como parte também dos processos de ensino. No campo da educação, quando se trata da transmissão de questões ligadas a traumas coletivos, a catástrofes históricas ou a tudo aquilo que resiste à representação, o ensino deve ser pensado dentro dos mesmos operadores de possibilidades e impossibilidades inerentes à transmissão dessas questões. A disciplina aconteceu, então, por meio do diálogo e da contínua reinvenção, 
levando em conta os efeitos e reverberações que as questões trabalhadas em aula foram produzindo nos estudantes e em nós, docentes.

\section{A crise em sala de aula}

Para entendermos a crise que veio a tomar conta da sala de aula é preciso situarmos, antes de mais nada, o modo como o próprio planejamento do semestre foi pensado. Ao optarmos por privilegiar referências bibliográficas e artísticas de cunho testemunhal, acabamos construindo um cronograma denso, tanto no sentido teórico quanto emocional. Decidimos, por exemplo, passar o documentário " 15 Filhos", de Maria Oliveira e Marta Nehring (1996), e alguns capítulos do livro "K.", de Bernardo Kucinski (2014), obras que lidam diretamente com as feridas ainda abertas da época da ditadura. Sabíamos, até certo ponto, que a forma como havíamos planejado a disciplina traria desafios. Contávamos que as discussões sobre os restos da ditadura civil-militar e suas marcas clínicas e políticas poderiam afetar as alunas e os alunos de diferentes maneiras. Não poderíamos ter imaginado, contudo, que o processo se desenrolaria com tanta intensidade e, acima de tudo, que o momento de turbulência política vivido no país faria disparar em sala de aula um processo testemunhal intenso dos próprios estudantes.

No domingo que antecedeu o nosso terceiro encontro com a turma, aconteceu o primeiro dos grandes protestos civis que tomaram conta das ruas nas principais capitais brasileiras durante o ano de 2016. Acompanhados pelos grandes veículos de comunicação do país, manifestantes exigiam, entre outras coisas, a saída imediata da Presidenta Dilma Rousseff. Alguns chegavam a pedir por uma intervenção militar para solucionar os conflitos políticos do país. Na aula seguinte, que tinha como tema justamente "os restos da ditadura entre os esforços democráticos", a discussão sobre o protesto envolveu o tempo e o espaço.

Diante de um discurso que afirmava que o processo de impeachment seria um novo "golpe em curso", a discussão da disciplina inevitavelmente transitava pela relação entre o que estávamos vivendo e os conceitos trabalhados; isto é, como uma possível repetição de algo que ainda não foi elaborado, algo especificamente relacionado aos escuros porões onde boa parte da memória da ditadura civil-militar ainda se encontra silenciada. As alunas e os alunos, no entanto, pareciam desconfiar da ligação tão simples que estava se costu- rando entre um período do passado e o presente; propondo, em contrapartida, que levássemos em conta uma série de outros fatores para pensar a violência estatal incrustada entre os frágeis alicerces de nossa atual democracia. "Não haveria outros momentos pouco elaborados de nossa história igualmente importantes para pensarmos as violências dos dias atuais?", interrogavam; "deveríamos olhar para os restos da ditadura ou para os efeitos de uma violência de origens ainda mais remotas?". Entendemos que, ao levantarem tais questões, não colocavam em jogo a relevância de nos debruçarmos sobre esse período específico do nosso passado, mas sugeriam que essa discussão ofuscava outros eventos que também são silenciados e, por sua vez, menos visibilizados.

Dessa forma, começava a se desenhar o que mais tarde viemos a nomear como uma crise em nosso processo de ensino. Algo emergiu nessas interrogações dos estudantes e permaneceu durante o semestre, ecoando questionamentos que ressoaram de maneira intensa entre nós, professores. Em busca de hipóteses para compreender os desafios do tempo presente, começamos a nos perguntar sobre as escolhas de textos para conduzir as discussões, pondo em xeque, gradualmente, as próprias direções do nosso olhar.

Em meio a tais indagações, chegamos ao fim do segundo módulo e algumas alunas pediram para compartilhar suas produções narrativas com a turma. Uma delas havia feito um trabalho de colagens sobre um cartaz. Ela deixou-o no meio da sala e convidou o grupo a observar. De um lado haviam sido coladas fotografias que mostravam a repressão e a violência de Estado na época da ditadura. O outro lado estava completamente coberto com imagens de diversos acontecimentos anteriores, também violentos, da história brasileira: repressões, revoltas, revoluções, massacres. Cada uma dessas imagens vinha acompanhada de uma legenda indicando a situação, o local e a data onde ocorreu. Porém, devido à grande quantidade de material retratado, as legendas eram pequenas, o que demandava que o grupo chegasse bem perto do cartaz para poder ler as informações. Quem se aproximava sentia um forte odor que o cartaz exalava devido ao sangue seco que atravessava as imagens.

O compartilhamento do trabalho gerou um tumulto. Como foi apresentado no fim de uma aula, o horário de saída foi ultrapassado e muitos já estavam se retirando. Seguiu-se uma discussão enérgica na classe, já que a saída de alguns foi interpretada por 
outros como um desrespeito ao trabalho da colega, bem como às vidas que estavam sendo retratadas no cartaz. Supostamente, assim se estaria ratificando o esquecimento e a violência aos quais essas vidas estiveram submetidas. O clima tenso durou alguns minutos. Aos poucos, a turma conseguiu debater sobre como o incômodo relacionado à imposição de um olhar se relacionava aos próprios paradoxos do exercício testemunhal.

$\mathrm{Na}$ aula seguinte, saindo do roteiro inicialmente previsto, propusemos à turma fazer uso dos conceitos que vínhamos estudando para refletir sobre o recente acontecimento, baseando-nos na hipótese de que o cartaz teria trazido à tona a aporia intrínseca à memória traumática. Por um lado, sua forma não permitia entender o conteúdo escrito em pequenas letras, a menos que nos aproximássemos. Por outro, o sangue seco exalava um odor desagradável que incomodava muito quando chegávamos perto. O trabalho produzia um efeito angustiante ao sugerir que o sangue vinha dos próprios cadáveres insepultos, dos tantos mortos atravessados pela história de desigualdade e injustiça que nos havia trazido até o Brasil de 2016. Também atualizava o próprio paradoxo que vínhamos tentando pensar: como se aproximar das histórias de violência? Como estudar o horror que carrega cada uma dessas imagens? Como escutar aquilo que desafia os limites do suportável? Parecia que estávamos vivendo em ato, nas nossas relações enquanto turma, as contradições inerentes ao testemunhar: entre a necessidade de falar e a impossibilidade de dizer, entre precisar lembrar e querer esquecer, entre tudo calar e algo falar, entre se aproximar e se distanciar.

Outrossim, uma vez que entendemos que a própriadinâmica dasala deaula poderiatornar-se palcode uma revivência da experiência traumática, tornou-se importante considerar o teor testemunhal do conflito instaurado. Entendemos que, em seus diversos questionamentos, as alunas e os alunos tentavam endereçar algo a nós professores. Na nossa leitura, estaria se formando aí também, entre os infinitos obstáculos do traumático, uma narrativa sobre suas próprias vivências. Em resposta a nossa sugestão de lançar o olhar sobre os restos da ditadura em seus estágios, projetos de pesquisa e extensão, os estudantes pareciam convocar nossa atenção para outras diversas violências às quais eles próprios estavam submetidos no dia-a-dia. Com seus testemunhos, levaram-nos a enxergar os restos dos demais episódios violentos retratados no outro lado do cartaz: genocídio da população jovem e negra, dificuldades dos estudantes cotistas dentro da universidade, criminalização dos movimentos sociais, entre outros. Não seriam esses também os restos que tínhamos nos proposto a estudar? Reminiscências do nosso passado pouco democrático?

Instalou-se em nosso processo de ensino uma crise que nos fez questionar nossas próprias escolhas como docentes. Entendemos que a modalidade de ensino testemunhal - que justamente se dispõe a acolher o que os alunos pensam e sentem - acabou oferecendo um lugar para que todas essas outras interrogações, atravessadas por narrativas traumáticas, emergissem no debate em sala de aula e viessem a perturbar a experiência de ensino. Podemos dizer que o choque, a soma e as sobreposições entre os textos, as questões trazidas pelos estudantes e os acontecimentos políticos do país, não poderiam senão produzir uma crise em nossa proposta inicial, tornando as aulas e discussões efervescentes, imprevisíveis e intensas.

Diante do que se desenhou em sala de aula, nossa intervenção como docentes foi de sustentar e acolher a crise ao invés de suprimi-la. Tal como a própria clínica psicanalítica se orienta em relação ao trauma, nossa intervenção se deu por meio da tentativa de escuta do que a turma enunciava; garantimos, assim, um tempo que desse suporte à iminente não resolução do que surgiu em aula, produzindo pausas no cronograma previsto e emprestando palavras e significações para os acontecimentos que pareciam sem sentido. Ao nos depararmos com críticas e problematizações, resolvemos viver o processo junto com os estudantes, percorrê-lo em seus movimentos, rupturas e imprevisibilidades. A importância de sustentar esse momento de inquietação, tensão, dúvidas e contestação de saberes pôde ser melhor observada à medida que percebemos que foi precisamente a crise o que recheou de sentidos nossos encontros seguintes. Ao propor à turma e a nós, docentes, que tentássemos traduzir em palavras o que havia aparecido em ato, críticas e apontamentos, acabamos produzindo uma mudança nas relações ali postas, a partir da qual a turma passou a se relacionar de outra forma com as questões estudadas.

Os trabalhos seguintes escritos pela classe, referentes aos últimos módulos, adquiriram outro tom: os estudantes passaram a falar sobre as temáticas das aulas desde sua própria posição, de um modo mais implicado. Os conteúdos teóricos e testemunhos 
estudados foram relacionados com suas vivências pessoais e profissionais, ora buscando estabelecer relações com experiências atuais, ora ressignificando episódios anteriores, articulando, de toda forma, as discussões de aula com seus percursos de formação. De certo modo, podemos dizer que esses escritos finais foram produzidos na forma de testemunhos dos percursos singulares de cada estudante, no encontro com os desafios e adversidades inerentes à formação.

\section{Considerações finais: a crise como ensino}

O presente relato teve por objetivo apresentar o exercício testemunhal como um método de ensino que tem na experiência vivida e compartilhada seu principal alicerce. A partir desse entendimento, ensinar e estudar não implicam somente ler teorias, mas sobretudo colocá-las em exercício, seja escutando e acolhendo o outro, seja construindo uma narrativa de sua própria história. Examinando a nossa experiência em retrospecto, podemos destacar três outras particularidades fundamentais e indissociáveis dessa proposta: seu caráter processual, sua dimensão clínica e seu estatuto ético-político.

Dizemos que é processual, pois o ensino testemunhal não está centrado em conteúdos pré-determinados a serem conduzidos de maneira unidirecional dos professores aos alunos, mas, acima de tudo, em discutir os próprios paradoxos inerentes ao exercício de transmissão. A ênfase não está no cumprimento do cronograma ou em metas a serem alcançadas, mas no próprio caminho percorrido, nos incômodos, percalços e incertezas atinentes às tarefas de narrar e escutar. Assim, por mais que se possa estruturar aulas, um quadro de referências bibliográficas e temas específicos a serem discutidos, acidentes e imprevistos fazem parte do percurso. Essa metodologia se propõe a acolher os efeitos gerados a partir dos encontros, fortuitos e intempestivos, promovidos pela dinâmica da sala de aula.

Em resumo, podemos dizer que o ensino na dependência de um processo testemunhal exige que se esteja aberto a encarar o imprevisível. No nosso caso, não contávamos com o que se apresentou como um choque entre a densidade emocional dos testemunhos estudados, as vivências dos alunos e um momento de turbulência política que explicitava as frágeis fundações de nossa democracia. Uma crise, conforme a denominamos, que no início apresentou-se como um questionamento à proposta de ensino, aos poucos foi compreendida como a emergência do traumático em sala de aula e, portanto, como a forma pela qual essa metodologia pôde, de fato, se desenrolar.

Nesse sentido, compreendemos que, muitas vezes, não há possibilidade de estudo que não seja a própria "vivência" dos conteúdos, uma vivência que extrapola planejamentos e preparações acadêmicas. Concordamos com Felman (2000): "se o ensinar não se depara com uma espécie de crise, se ele não encontra nem a vulnerabilidade nem a explosividade de uma dimensão crítica e imprevisível [...] , ele provavelmente não ensinou verdadeiramente" (p. 67). A tarefa do professor em um ensino na dependência do processo testemunhal não é, portanto, simplesmente passar adiante informações preconcebidas; mas, ao ensinar, fazer algo acontecer. De acordo com a autora, trata-se de um ensino que é performativo, e não apenas cognitivo, na medida em que convoca seus receptores a se transformarem em função da novidade da informação transmitida.

A segunda particularidade a ser destacada sobre $o$ ensino testemunhal é sua dimensão clínica. Se entendermos que, em muitas experiências de violência há uma impossibilidade de narrar - tanto pelo caráter traumático quanto pela ausência de reconhecimento e legitimidade -, a criação de um espaço que garanta a circulação da palavra e o endereçamento a um outro permite que seja possível a construção de alguma história sobre o que se passou. No testemunho há sempre uma aposta: de que olhar para o passado, em uma postura crítica, pode instaurar um outro porvir. Uma aposta não necessariamente na capacidade do sujeito de representar aquilo que foi vivido como excesso, mas na transformação da relação que os sujeitos e que a própria sociedade estabelece com aquilo que nunca poderá ser totalmente recoberto de sentido. O ensino testemunhal compromete-se, assim, com uma tentativa de interrupção de uma cadeia de repetições de violência e com a definição de alguns princípios que possam nortear a tarefa de recepção do testemunho e de costuras possíveis, mesmo que imperfeitas, com o laço social.

Chegamos ao terceiro aspecto fundamental do ensino testemunhal: seu estatuto ético-político. Devido ao caráter subjetivo e fragmentário, o testemunho ocupa um espaço marginal na escrita oficial da história, que é baseada em documentos, provas verificáveis e métodos científicos. Como diria Benjamin (1996), a história oficial, no entanto, reflete invariavelmente a duvidosa versão dos vencedores. 
E a história oficial brasileira, ainda falha em reconhecer e dar a devida importância aos abusos cometidos pelo Estado durante a ditadura civil-militar, opta reiteradamente por condenar ao esquecimento os efeitos dessas violências em favor da manutenção do poder de uma mesma elite, que antigamente patrocinava a ditadura e que ainda hoje colhe frutos às custas do silêncio (Endo, 2015).

A modalidade do ensino testemunhal possibilita uma formação crítica, pois desconstrói a ideia de uma história neutra e torna visível que ela é, sobretudo, uma construção feita no presente e imanente a disputas políticas. Uma formação crítica do fazer $p s i$ - que se contraponha à primazia da técnica e da pretensa "neutralidade" e que forme profissionais capazes de trabalhar memórias de violências e de desigualdades de nosso país - talvez só possa acontecer por meio de um exercício ético em que coloquemos em análise nossas implicações.

Por fim, sublinhamos que essas três particularidades do ensino testemunhal se relacionam fortemente aos próprios desafios da construção da memória da ditadura civil-militar no Brasil e, como apontado pelos estudantes, de toda nossa história de violência. A tessitura de uma narrativa sobre esses períodos - uma que nos permita recordar, elaborar e não apenas repetir - demanda mais do que apenas "informações históricas". Precisamos, é claro, que se tenha acesso a um sem número de documentos de cujo paradeiro até hoje não se tem notícia; assim como é necessário que haja um reconhecimento oficial das atrocidades cometidas durante os anos vividos sob Estado de exceção e a responsabilização dos agentes perpetradores dessas violências. Mas existe algo além da "história objetiva" e da "justiça oficial", algo do traumático que se repete e que apenas o testemunho, sob a aporia de sua própria impossibilidade e imprevisibilidade, tem condições de fazer emergir. Para que a sociedade brasileira possa realmente se ocupar dos "restos da ditadura", portanto, deve também escutar a si mesma ainda que isso implique uma crise, pois é apenas a partir desse ato ético e político que algo realmente pode se transformar. Ao menos essa foi a lição que aprendemos com nossos alunos.

\section{Referências}

Agamben, G. (2008). O que resta de Auschwitz: o arquivo e a testemunha. São Paulo, SP: Boitempo.

Benjamin, W. (1996). Sobre o conceito de história. In W. Benjamin, Obras escolhidas: magia e técnica, arte e política (pp. 222-232). São Paulo, SP: Brasiliense.

Benjamin, W. (2014). Imagens de pensamento: sobre o haxixe e outras drogas. Belo Horizonte, MG: Autêntica.

Brasil. (1977, 20 de junho). Decreto no 79.822, de 7 de junho de 1977. Regulamenta a Lei no 5.766, de 20 de dezembro de 1971, que criou o Conselho Federal e os Conselhos Regionais de Psicologia e dá outras providências. Brasília, DF: Presidência da República.

Coimbra, C. (2009). Gênero, militância e tortura. In J. C. Mourão (Org.), Clínica e política 2: subjetividade, direitos humanos e invenção de práticas clínicas (pp. 21-33). Rio de Janeiro, RJ: Abaquar.

Endo, P. C. (2005). A violência no coração da cidade: um estudo psicanalítico sobre as violências na cidade de São Paulo. São Paulo, SP: Escuta.

Endo, P. C. (2015). Ainda um esforço pela claudicante democracia à brasileira. Correio da APPOA, (246). Recuperado de http://www.appoa.com.br/correio/edicao/246/ainda_um_esforco_pela_claudicante_democracia_a_brasileira/215

Felman, S. (2000). Educação e crise, ou as vicissitudes do ensino. In A. Nestrovski, \& M. Seligmann-Silva, Catástrofe e representação (pp. 13-71). São Paulo, SP: Escuta.

Freud, S. (2010). Além do princípio do prazer. In S. Freud, Obras completas (vol. 14, pp. 161-239). São Paulo, SP: Companhia das Letras. (Trabalho original publicado em 1920).

Gagnebin, J. M. (2006). Lembrar escrever esquecer. São Paulo, SP: Editora 34.

Gagnebin, J. M. (2010). O preço de uma reconciliação extorquida. In E. Teles, \& V. Safatle (Orgs.), O que resta da ditadura: a exceção brasileira (pp. 177-186). São Paulo, SP: Boitempo.

Kucinski, B. (2014). K.: relato de uma busca. São Paulo, SP: Cosac Naify 
Kupferberg, M. (2009). Zonas de silêncio e segredo familiar: a transmissão interrompida. In E. Schweidson (Org.), Memória e cinzas (pp. 103-124). São Paulo, SP: Perspectiva.

Laub, D. (1995). Truth and testimony: the process and the struggle. In C. Caruth (Org.), Trauma: explorations in memory (pp. 61-75). Baltimore, MD: The John Hopkins University Press.

Nardi, H. C., \& Silva, R. N. (2004). A emergência de um saber psicológico e as políticas de individualização. Educação \& Realidade, 29(1), 187-197. Recuperado de http://seer.ufrgs.br/index.php/educacaoerealidade/article/ view/25425/14751

Nestrovski, A., \& Seligmann-Silva, M. (2000). Apresentação. In A. Nestrovski, \& M. Seligmann-Silva (Orgs), Catástrofe e representação (pp. 7-12). São Paulo, SP: Escuta.

Oliveira, M. ,\& Nehring, M. (Diretoras). (1996). 15 Filhos [DVD].

Ortega, F. A. (2011). El trauma social como campo de estudios. In Ortega, F. A., Trauma, cultura e historia: reflexiones interdisciplinarias para el nuevo milênio (pp. 17-59). Bogota: Universidad Nacional.

Rose, N. (2008). Psicologia como uma ciência social. Psicologia \& Sociedade, 20(2), 155-164. Recuperado de https:// social.stoa.usp.br/articles/0038/4451/rose_nikolas._psicologia_como_uma_ci_ncia_social.pdf

Scarparo, H. B. K., Torres, S., \& Ecker, D. D. I. (2014). Psicologia e ditadura civil-militar: reflexões sobre práticas psicológicas frente às violências de estado. Revista EPOS, 5(1), 57-78. Recuperado de http://pepsic.bvsalud.org/ scielo.php?script=sci_arttext\&pid=S2178-700X2014000100004

Seligmann-Silva, M. (2000). História como trauma. In A. Nestrovski M., \& Seligmann-Silva (Orgs), Catástrofe e representação (pp. 73-98). São Paulo, SP: Escuta.

Seligmann-Silva, M. (2005). Testemunho e a política da memória: o tempo depois das catástrofes. Projeto História. Revista do Programa de Estudos Pós-Graduados de História, (30), 71-98. Recuperado de https://revistas.pucsp.br/ index.php/revph/article/view/2255/1348

Teles, E., \& Safatle, V. (2010). O que resta da ditadura: a exceção brasileira. São Paulo, SP: Boitempo.

\section{Helena Pillar Kessler}

Mestre em Psicanálise: Clínica e Cultura pela Universidade Federal do Rio Grande do Sul, Porto Alegre - RS. Brasil.

E-mail: helenapkessler@gmail.com

\section{Daniel Boianousky Kveller}

Doutorando em Psicologia Social e Institucional pela Universidade Federal do Rio Grande do Sul, Porto Alegre - RS.

Brasil.

E-mail: dkveller@gmail.com

\section{Marina da Rocha Rodrigues}

Mestre em Psicologia Social e Institucional pela Universidade Federal do Rio Grande do Sul, Porto Alegre - RS. Brasil.

E-mail: marinarocharodrigues@gmail.com

\section{Karine Shamash Szuchman}

Mestre em Psicologia Social e Institucional pela Universidade Federal do Rio Grande do Sul, Porto Alegre - RS. Brasil.

E-mail: karineszuchman@gmail.com

Endereço para envio de correspondência:

Rua Anita Garibaldi, 1199/701. Bairro Mont' Serrat. CEP: 90450-001.

Porto Alegre - RS. Brasil. 
Recebido 30/06/2017

Reformulação 30/09/2017.

Aprovado 02/10/2017.

Received $06 / 30 / 2017$

Reformulated 30/09/2017

Approved 10/02/2017

Recebido 30/06/2017

Reformulado 30/09/2017

Aceptado 02/10/2017

Como citar: Kessler, H. P., Kveller, D. B., Rodrigues, M. R., Szuchman, K. S. (2017). O ensino testemunhal entre os restos da ditadura: uma metodologia ético-política. Psicologia: Ciência e Profissão, 37(n. spe), 161-171. https://doi.org/10.1590/1982-3703120002017

How to cite: Kessler, H. P., Kveller, D. B., Rodrigues, M. R., Szuchman, K. S. (2017). Testimonial teaching among the remains of the dictatorship: an ethical-political methodology. Psicologia: Ciência e Profissão, 37(n. spe), 161-171. https://doi.org/10.1590/1982-3703120002017

Cómo citar: Kessler, H. P., Kveller, D. B., Rodrigues, M. R., Szuchman, K. S. (2017). La enseñanza testimonial entre los restos de la dictadura: una metodología ético-política. Psicologia: Ciência e Profissão, 37(n. spe), 161-171. https://doi.org/10.1590/1982-3703120002017 